\title{
Os Modelos de Administração Pública como Estratégias Complementares para a Coprodução do Bem Público
}

\author{
José Francisco Salm ${ }^{1}$ \\ Maria Ester Menegasso ${ }^{2}$
}

\begin{abstract}
Resumo
A administração pública é reconceituada com base na teoria da delimitação dos sistemas sociais, que tem como foco de estudo a sociedade politicamente articulada, a partir da concepção do que é o ser humano, como artífice, da construção dessa sociedade. Considerada essa reconceituação, são discutidos os modelos de administração pública, com o propósito de demonstrar a sua complementaridade e a rede de coprodução do bem público de que fazem parte. A existência humana se realiza em múltiplos espaços, cada qual com exigências e necessidades próprias. A essa realidade social é que se aplicam os modelos de administração pública. Quando analisados sob essa perspectiva, tais modelos são complementares entre si, cada um com o seu espaço de aplicabilidade na sociedade politicamente articulada; por via de consequencia, o bem público é coproduzido em rede, e dessa rede, assim como as outras instâncias comunitárias que compõem a sociedade, fazem parte esses diversos modelos. A partir dessa complementaridade dos modelos e da coprodução do bem público, algumas considerações são feitas sobre o estudo e a pesquisa em administração.
\end{abstract}

Palavras-chave: Administração pública. Modelos. Coprodução.

Complementaridade. Multidimensionalidade.

\section{Introdução}

A administração pública, desde o seu início, fez uso da organização burocrática como principal estratégia para alocar recursos e produzir o bem público. Vista dessa forma, a administração pública "é a mais evidente parte

\footnotetext{
${ }^{1}$ Doutorado (Ph.D.) em Administração Pública pela Universidade do Sul da California (USC - EUA). Professor da Universidade do Estado de Santa Catarina - UDESC. Endereço: Av. Madre Benvenuta, 2007 - Florianópolis - SC. E-mail:jfsalm@uol.com.br.

${ }^{2}$ Doutorado em Engenharia de Produção pela Universidade Federal de Santa Catarina, UFSC. Professora da Universidade do Estado de Santa Catarina - UDESC. Endereço: Av. Madre Benvenuta, 2007 - Florianópolis - SC. E-mail: menester@uol.com.br. Artigo recebido em: 03/ 03/2009. Aceito em: 15/07/2009. Membro do Corpo Editorial Científico responsável pelo processo editorial: Rolando Juan Soliz Estrada.
} 
do governo; é o governo em ação, é o executivo, operante, o mais visível aspecto do governo..." (WILSON, 1887, p.199). Em um segundo momento, a administração pública passou a tratar, também, da formulação, da implementação e da avaliação da política pública (WALDO, 1980). Esse modelo de administração pública é denominado, por alguns autores, administração convencional ou velha administração pública (DENHARDT, DENHARDT, 2003).

A partir das últimas décadas do século passado, os dilemas impostos pelos limites fiscais tornaram o estado do bem-estar social inviável e a administração pública passou a ser vista apenas sob o prisma da eficiência, da redução dos gastos públicos e dos cortes orçamentários. Em tais condições, ela foi reduzida à instrumentalidade do mercado, não compartilhando a esfera ou o domínio público (ARENDT, 1958; GOODSELL, 2003; CAMPBELL, 2005) ou, ainda, a sociedade politicamente articulada (VÖEGELIN, 1952). Esse modelo de administração pública, denominado nova gestão pública, transformou o cidadão em cliente ou consumidor a quem cabe fazer escolhas, como se estivesse na esfera privada (BARZELAY, 2001).

Esses modelos de administração pública - com exceção de propostas isoladas - foram concebidos a partir de categorias epistemológicas que consagram a burocracia como referência para a produção dos serviços públicos e o mercado como o melhor alocador do bem público. A crítica que esses modelos vêm sofrendo também está relacionada com essas bases epistemológicas. Assim, a velha administração pública, com a sua impessoalidade e forma de dominação, é vista como ineficiente e de elevado custo (KETLL, 2000), enquanto a nova gestão pública, ancorada no mercado, é criticada por descaracterizar a esfera pública e a democracia (SPICER, 2004; BATTISTELLI, RICOTA, 2005; POTOSKI, PRAKASH, 2004; VENTRISS, 2002).

Algumas propostas isoladas e emergentes de administração pública estruturaram a sua base epistemológica a partir dos princípios que caracterizam a esfera pública e a democracia. Com base nesses princípios, tais propostas contêm críticas ao modelo da velha administração pública e à nova gestão pública (BELLONI, 1980; DENHARDT, DENHARDT, 2003). Mas essas propostas também são frágeis, porque não oferecem estratégias para tornar eficiente a produção e a alocação do bem público.

Em suma, o modelo da velha administração pública é ineficiente e oneroso para a sociedade, a nova gestão pública enfatiza a esfera privada em 
detrimento da esfera pública e as propostas emergentes propõem poucas ações para superar os problemas dos demais modelos. Quando analisados sob tais prismas, isoladamente, os modelos de administração pública são pouco eficazes para produzir e alocar o bem público para a sociedade. Contudo, a sociedade a quem a administração pública serve não é constituída de um modelo puro, isolado e de um único espaço linear para a existência humana. Pelo contrário, a sociedade é constituída de múltiplos espaços e modelos (RAMOS, 1981; SANTOS, 1988).

Portanto, os modelos e as propostas emergentes de administração pública não podem ser analisados e criticados como se cada um deles fosse um fenômeno único, isolado, aplicado à sociedade como um todo homogêneo. Em outros termos, os modelos e as propostas de administração pública aplicam-se à realidade social em que há múltiplos espaços para a existência humana, cada qual com suas exigências e necessidades próprias. Considerados sob esse prisma, os modelos integram a administração pública e são necessários à sociedade politicamente articulada e ao cidadão que dela faz parte. Cabe, agora, discutir e demonstrar a validade dessa assertiva.

Este artigo tem como objetivo demonstrar que os modelos e as propostas de administração pública, quando analisados sob uma mesma base epistemológica, são complementares entre si, cada um com o seu espaço de aplicabilidade na sociedade politicamente articulada; por via de consequência, que o bem público é coproduzido em rede, da qual fazem parte esses diversos modelos e propostas, assim como outras instâncias que compõem a sociedade.

Para atingir esse objetivo, é necessário, além desta (1) introdução, (2) reconceituar a administração pública a partir de uma base teórica que tenha como foco de estudo a sociedade politicamente articulada e a concepção do que é o ser humano, como artífice, na construção dessa sociedade. A teoria da delimitação dos sistemas sociais, quando estudada sob o prisma de uma sociedade multicêntrica, oferece essa base teórica. Ainda com base nessa reconceituação, os (3) modelos e propostas de administração pública podem ser rediscutidos com o propósito de demonstrar a sua complementaridade $e$ a rede de coprodução do bem público da qual fazem parte. Algumas (4) considerações acerca do estudo e da pesquisa sobre a administração pública $e$ a listagem das (5) referências encerram este artigo. 
José Francisco Salm • Maria Ester Menegasso

\section{A Reconceituação da Administração Pública com Base na Teoria da Delimitação dos Sistemas Sociais}

Com o propósito de reconceituar administração pública, serão aqui discutidas as principais categorias epistemológicas da teoria da delimitação dos sistemas sociais. Essas categorias serão ordenadas com base na concepção de (1) ser humano; de (2) sociedade, mercado e organizações. O fecho se fará com a (3) reconceituação de administração pública.

É necessário esclarecer que, neste artigo, a teoria da delimitação dos sistemas sociais não será enfocada em toda a sua complexidade. O propósito é, tão somente, dela extrair as categorias epistemológicas necessárias à reconceituação da administração pública.

\subsection{A Concepção de Ser Humano}

O ser humano, na concepção da teoria da delimitação dos sistemas sociais, é um ser único e multidimensional. Único, porque só ele pode agir e analisar as suas ações com liberdade, encontrando nelas legitimidade ou não. Portanto, só ele pode ser responsável, perante si mesmo, pelas ações que lucidamente realizar, sob o império da razão. Multidimensional, porque é, ao mesmo tempo, um animal político, social e econômico (CORNFORD, 1976). Ele é, por excelência, um ser que necessita participar com os outros e da participação dos outros para construir a sua existência e a dos outros (ROBERTS, 2004). Por isso o ato de participação na esfera pública, inclusive coproduzindo o bem público, pertence à condição humana, ele é inerente ao animal político. O ser humano pode viver a sua existência integralmente graças ao uso da razão que lhe proporciona a consciência da realidade da própria vida (VÖEGELIN, 1977). O enfoque seguinte trata da concepção de sociedade, mercado e organizações.

\subsection{Concepção de Sociedade, Mercado e Organizações}

A teoria da delimitação dos sistemas sociais categoriza os espaços da existência humana em fenonomia, isonomia e economia, e foca primordialmente esses espaços em lugar de priorizar a sociedade como um todo. Arendt (1958) faz a mesma projeção ao confrontar a esfera pública com a esfera 
privada. No âmbito da teoria que orienta esta discussão, cabe, portanto, em vez da análise da sociedade, a análise dos espaços da existência humana.

O conceito de espaço segue o pensamento de Santos (1988). Esse autor define espaço como um fato que perpassa o mundo concreto, positivo, $e$ o mundo das ideias. No mundo concreto, positivo, ele é o espaço físico de que necessita o geógrafo para compor os seus mapas ou o arquiteto para elaborar os seus projetos. No mundo das ideias, ele é o espaço da história e da convivialidade humana, impossível de ser medido por uma escala métrica. Ele é o espaço da existência humana que transcende as aparências. Embora não possa ser ele medido por um aparato físico, negar que exista é negar a existência da mente e do próprio ser em sua condição humana.

A fenonomia é um espaço pessoal, do ser político, necessário à existência humana. Em um mundo sem espaços verdadeiramente pessoais, fenece a razão, a ética, a unicidade e a multidimensionalidade humana e o equilíbrio da mente. Sem esse espaço, o ser humano se brutaliza, se aliena de si próprio e apenas reage de acordo com a regra social (VÖEGELIN, 1978).

A isonomia é o espaço dos iguais, da comunidade e da democracia participativa ou comunal. As organizações sociais encontram no espaço isonômico o seu habitat por excelência. Sem espaços isonômicos, o ser humano perde a sua relação de igualdade com o outro, sua capacidade de concretizar o seu fazer com os outros. Pior, perde a tensão existencial, necessária para a realização do sentido da vida (FRANKL, 1991). O espaço isonômico é apropriado para o desenvolvimento de organizações sociais que, além de produzir bens e serviços, oferecem a oportunidade para o exercício da convivialidade e da realização pessoal (MASLOW, 1943; GERMINO, 1982).

A economia é um espaço de desiguais, em que se legitima a dominação (WEBER, 1978). Ela se caracteriza pela eficiência para a produção e alocação de bens e serviços. É um espaço também necessário à existência da vida, pois, sem ele, não poderiam ser satisfeitas muitas das necessidades humanas, tanto as de natureza primária, quanto secundárias e terciárias. O espaço econômico é, pois, imprescindível à existência humana.

O espaço da economia abrange o mercado, como alocador de bens e serviços, bem como as organizações formais. Essas organizações foram estudadas exaustivamente nos últimos anos. Não se esgotou, todavia, o entendimento desses espaços complexos de produção de bens e serviços. As questões relativas à ação administrativa foram estudadas por Ramos (1983) quando expôs os problemas relacionados com a racionalidade nas organizações, 
a ética e as suas tensões, o poder e a alienação, o envolvimento e o consentimento das pessoas, a superconformidade e a reificação. As questões levantadas pelo autor sobre as estruturas de consentimento nas organizações do tipo participativo merecem mais estudo, principalmente quando ocorrem no espaço de burocracias que produzem o bem público.

Permeando a sociedade, existem algumas formas de organização que não estão sob o predomínio da instrumentalidade do mercado. Nessa forma de organização, muitas pessoas trabalham, enquanto outras se ocupam. $\mathrm{O}$ trabalho é entendido como

[...] a prática de um esforço subordinado às necessidades objetivas inerentes ao processo de produção em si. A ocupação é a prática de esforços livremente produzidos pelo indivíduo em busca de sua atualização pessoal (RAMOS, 1981, p.130).

Por ser a ocupação uma categoria essencial às organizações sociais, há necessidade de limitar imposições e regras desnecessárias. Também há necessidade de fomentar as práticas participativas entre os membros da organização, com o objetivo de determinar as regras mínimas da convivialidade nesses espaços predominantemente isonômicos.

\subsection{A Reconceituação da Administração Pública}

A administração pública, sob o prisma da teoria da delimitação dos sistemas sociais, estrutura-se sobre algumas categorias que são essenciais quando se concebe a pessoa humana como um ser único, a requerer uma sociedade multicêntrica para exercer a sua multidimensonalidade.

Tais categorias, no seu conjunto, compõem as bases para a reconceituação de administração pública. Antes, porém, torna-se necessário retornar ao conceito de administração pública de Wilson (1887) acrescentando as definições de administração pública utilizadas por Waldo (1980). As definições de que se apropria Waldo para discutir o que é a administração pública afirmam que "[...] é a organização e a gestão das pessoas e dos materiais necessários para alcançar os propósitos do governo”. Na continuação, ele afirma que "a administração pública é a arte e a ciência da gestão aplicada aos negócios do estado". Enquanto Wilson foca a administração pública 
como o governo ou o executivo, as duas definições apresentadas por Waldo se referem à administração pública como governo ou negócios do estado. Tanto o conceito apresentado por Wilson como as duas definições adotadas por Waldo restringem a administração pública ao governo ou ao estado. Falta ao conceito e às definições, a inclusão do ser humano atuante na esfera pública como o provedor de serviços públicos. Falta, também, incluir as organizações sociais como instituições aquém do governo e do estado, capazes de produzir o bem público para o cidadão e para a sociedade. Com base na discussão das categorias e na breve análise do conceito e definições realizadas anteriormente, cabe agora reconceituar a administração pública.

Assim, a administração pública é um conjunto de conhecimentos e de estratégias em ação para prover os serviços públicos - bem comum - para o ser humano, considerado em suas múltiplas dimensões e como cidadão partícipe de uma sociedade multicêntrica articulada politicamente.

Nesse conceito estão incluídas as diversas categorias discutidas neste documento, extraídas da teoria da delimitação dos sistemas sociais. Por exemplo, a unicidade e a liberdade do ser humano integram o conceito de cidadania que se constitui na "obrigação de defesa da cidade e de contribuição para seu bem-estar geral e o direito de opinar sobre seus destinos" (JAGUARIBE, 1982, p. 3). Portanto, cada cidadão, por ser único e livre, tem condições de agir e de participar, integralmente, da comunidade e, por conseguinte, da administração pública (PATTAKOS, 2004).

Consoante o conceito aqui desenvolvido, a democracia é essencial para a administração pública, uma vez que, sem ela, é inconcebível haver articulação política na sociedade. Da mesma forma, as dimensões do capital social (PUTNAM, 2000) são indispensáveis à administração pública e ao desenvolvimento em geral.

A administração pública vista sob a perspectiva da multidimensionalidade humana também requer a instrumentalidade do mercado própria das organizações econômicas. Portanto, a administração pública, enquanto estratégia em ação para prover o serviço público, também faz uso da organização burocrática, além de outras formas organizacionais, comunitárias e pessoais, para a produção dos serviços públicos. Isso significa que critérios de eficiência da ação administrativa na produção do bem público também são importantes.

A discussão do conceito de administração pública poderia estender-se no desenrolar deste artigo; no entanto, os detalhes das categorias que o inte- 
José Francisco Salm • Maria Ester Menegasso

gram continuarão a ser elaborados ao longo do próximo tópico, que trata dos modelos de administração.

\section{Os Modelos e as Propostas de Administração Pública como Estratégias que se Complementam na Coprodução do Bem Público}

A tentativa de agrupar as práticas administrativas sob grandes categorias tem sido muitas vezes frustrante. As escolas de administração e os modelos de gestão são dois exemplos que ilustram esse caso. Na raiz dessa frustração está o grau de generalidade e amplitude que alcança a administração, bem como o fato de modelos serem incapazes de abranger toda a singularidade da realidade. Feita essa ressalva, para os propósitos deste artigo, adotase a divisão dos modelos de administração pública desenvolvida por Ketll (2000) e complementada por Denhardt e Denhardt (2003), por ser bastante completa e incorporar um modelo emergente. Segundo esses autores, é possível listar os três principais modelos de administração pública, a saber: a administração pública convencional, também identificada como a velha administração pública; a nova gestão pública; e o modelo ou proposta emergente denominada o novo serviço público. A cada um desses modelos corresponde uma série de outras práticas ou iniciativas que serão indicadas ao longo deste tópico.

Os modelos de administração pública têm uma base de valores que remete a discussão ao tópico anterior. Afinal, cada modelo tem a sua base epistemológica e os limites que ela lhe impõe. Por isso mesmo, ao apresentar os (1) modelos e as propostas de administração pública, é necessário que se discuta, também, o paradigma que sustenta cada um deles. Feito isso, será necessário confrontar cada modelo com as categorias extraídas da teoria da delimitação dos sistemas sociais e com o conceito de administração pública elaborado a partir dessas categorias, visando (2) demonstrar a sua complementaridade. 


\subsection{Os Modelos e a Proposta de Administração Pública}

O primeiro modelo é conhecido como administração pública convencional ou a velha administração pública. Esse modelo está presente nas grandes burocracias do estado, tais como ministérios, secretarias de estado e fundações.

O modelo convencional, sob a perspectiva da burocracia patrimonial, foi adotado no Brasil por Dom João VI, no início do Século XIX, com a instalação do governo (WILCKEN, 2004), dando sequência a uma serie de reformas até nossos dias (GAETANI, 2003; MARINI, 2003). O modelo convencional foi e continua sendo, em larga escala, o aparato que o estado possui para produzir o serviço público. Suas origens são as da burocracia, conforme concebida por Weber (1978). As principais vertentes desse modelo são o modelo clássico da burocracia, o modelo neoclássico, o modelo institucional, o modelo das relações humanas, o modelo denominado public choice, cabendo também mencionar o modelo racional. Pode-se afirmar, com a ressalva apresentada no início deste tópico, que o modelo convencional de administração pública é representado pelo conjunto dessas abordagens. Seria possível, também, subdividir o modelo convencional, para que cada uma dessas vertentes se constitua em um submodelo.

A implementação do modelo da administração pública convencional implica a criação formal da organização, definição de objetivos, estruturação, adoção de tecnologias e desenvolvimento do processo cognitivo pelo corpo funcional a quem compete exercer as funções e papéis organizacionais. As funções administrativas exercidas pelos administradores públicos não fogem às clássicas funções do administrador. $O$ envolvimento do cidadão com os afazeres da organização não é considerado como uma das estratégias para a produção do bem público, a menos que seja para cooptá-lo para alcançar maior eficiência e menor custo na realização dos serviços. Mesmo nesse caso, espera-se que o poder discricionário dos administradores públicos seja reduzido, devendo responder pelos seus atos os agentes políticos. Aos administradores públicos, na concepção do modelo de administração pública convencional, cabe implementar as políticas públicas definidas pelo grupo eleito para exercer o poder político, exceto no caso do modelo ou submodelo de políticas públicas. O modelo se sustenta na premissa de que o serviço público pode ser produzido por meio da busca dos interesses da burocracia e que, por si só, é suficiente para a produção do bem público. Mas a prática tem 
demonstrado o contrário, mesmo porque, em uma sociedade moldada pelo paradigma do interesse próprio, as organizações formais, entre as quais as públicas, também se amoldam ao mesmo paradigma (HIRSCHMAN, 1978). Essa realidade sujeita a organização da burocracia pública a muitos desvirtuamentos, uma vez que os interesses das corporações dos seus funcionários ou os interesses de grupos privados podem prevalecer sobre o interesse público ou do cidadão.

O modelo de administração pública convencional vem sofrendo muitas críticas pela sua incapacidade de produzir a contento os serviços públicos. Os custos e a ineficiência da administração pública que adota esse modelo são cada vez maiores, principalmente quando está sob o imperativo dos limites fiscais. Não se pode deixar de citar o fato de que as pessoas buscam cada vez mais os serviços públicos, enquanto aumenta o grau de complexidade dessas demandas. O modelo convencional da administração pública tem demonstrado pouca qualificação para dar resposta ao aumento de custos e ao grau de complexidade dessas demandas. Por isso mesmo, há muita frustração com o modelo, levando muitos governos, já na década de 80 do século passado, a buscar modelos mais eficientes e capazes de superar as deficiências da burocracia, principal aparato do modelo de administração pública convencional.

O segundo modelo, denominado a nova gestão pública, surgiu como resposta às deficiências do modelo convencional. Esse modelo congrega também o modelo da reinvenção do governo implantado nos Estados Unidos, ambos têm raízes no modelo da public choice, já mencionada neste texto. Ao descrever o modelo da nova gestão pública, Ketll (2000) e Spicer (2004) identificam as raízes desse movimento com a busca pela produtividade, ou seja, pela forma como o governo pode produzir com menos gastos; adotar mecanismos de mercado para superar as deficiências da burocracia; dar feição de consumidor ao usuário dos serviços públicos; descentralizar os serviços; tornar o fornecedor desses serviços responsável perante o consumidor final; privatizar os serviços; e, finalmente, adotar a gestão por resultados. Todas elas, práticas identificadas com a gestão privada dos negócios.

Como já foi descrito antes, as mudanças políticas que ocorreram na década de 80, associadas a mudanças sociais, econômicas e institucionais, tornaram o campo fértil para que esse modelo fosse adotado por diferentes nações nas Américas, na Europa e na Ásia. Os países que mais se distinguiram na implantação do modelo são a Nova Zelândia, a Austrália e a Inglater- 
ra. Os principais autores que sustentam esse modelo são Allen Schick, David Osborn, Ted Gaebler e Al Gore. No Brasil, Bresser Pereira é um autor que se identifica com essa corrente.

A crítica que se faz a esse modelo está associada à filosofia de mercado que o sustenta; aos resultados que ele produziu, quando comparado a suas promessas; à frustração causada por não ter transformado as funções essenciais do estado e por não conter um novo padrão capaz de transformar a prática e a teoria de administração pública. A crítica avança mais quando se compara a administração pública convencional com a nova gestão pública e se conclui que ambas têm a mesma base paradigmática e utilizam a burocracia como estratégia para produzir o bem público. Em síntese, o modelo da nova administração pública utiliza as organizações privadas e públicas para produzir o bem público, enquanto a administração pública convencional utiliza a organização pública com o mesmo objetivo. Na realidade, o que muda é a estratégia que busca a eficiência do estado junto ao mercado. Para alcançar esse propósito, a esfera pública fica à mercê da esfera privada, e o cidadão como ente político é transformado em consumidor ou cliente. O modelo também tem recebido críticas porque pode tornar frágil a democracia (deLEON, DENHARDT, 2000; BOX, MARSHALL, REED, REED, 2001; COSTA, 2000; TERRY, 2005).

A proposta do novo serviço público é o terceiro modelo de administração pública. Esse modelo constitui-se em uma proposta emergente cujos contornos remontam às décadas de 70 e 80. Entre os autores que contribuíram com a proposta estão H. George Frederickson, Carl J. Bellone, Lloyd G. Nigro, Frederick C. Thayer, Ross Clayton, Michael M. Harmon, David K. Hart, Robert B. Denhardt e outros, além do brasileiro Alberto Guerreiro Ramos. Recentemente, Denhardt e Denhardt (2003) elaboraram a base epistemológica do modelo do novo serviço público. Essas bases tomam por princípio que o ser humano é, antes de mais nada, um ser político que age na comunidade; que a comunidade politicamente articulada requer a participação do cidadão para a construção do bem comum; e que o bem comum precede a busca do interesse privado.

A administração pública, em consonância com a proposta dos autores desse modelo, caracteriza-se por: servir aos cidadãos, não aos consumidores; estar a serviço do interesse público; emprestar mais valor à cidadania do que ao empreendedorismo; pensar estrategicamente e agir democraticamente; reconhecer que a accountability não é simples; servir ao cidadão, em vez de 
controlar e dirigir a sociedade; e valorizar as pessoas, não apenas a produtividade. A função principal do administrador público, segundo esse modelo, é fomentar a democracia enquanto produz ou coproduz o serviço público (DENHARDT, DENHARDT, 2003).

O foco central desse modelo de administração pública é servir ao interesse público. Os autores conceituam interesse público como o "resultado do diálogo sobre valores compartilhados" (DENHARDT, DENHARDT, 2003, p. 67). Comunidade, sociedade civil e cidadania são conceitos centrais ao modelo. Também o são, a virtude cívica, a participação e o envolvimento, bem como, o serviço público como extensão da cidadania.

Embora o novo serviço público contenha princípios merecedores de consideração por seu cunho democrático, a proposta ainda requer elaboração para que possa ser implementada. Analisada, isoladamente, a proposta se recente de práticas administrativas que sejam mais consistentes do que aquelas dos demais modelos. Ela não oferece uma estratégia para tornar eficiente o uso da organização burocrática e do mercado para a produção do bem público. É necessário levar-se em conta que o novo serviço público e os modelos da administração pública convencional e da nova gestão pública se estruturam sobre bases epistemológicas diferentes. Ademais, o novo serviço público se conforma ao espaço público enquanto os outros dois modelos utilizam diversas estratégias que pertencem à esfera privada. Evidencia-se, pois, que a proposta do novo serviço público foi formulada a partir de princípios diversos daqueles dos demais modelos. Logo, quando o novo serviço público se propõe a incorporar a administração pública convencional e a nova gestão pública como estratégias alocativas e de produção do bem público, ele o faz sem considerar as diferenças que existem nas bases epistemológicas desses modelos.

Em que pesem essas críticas, a proposta do novo serviço público é credora de estudos exaustivos, por seu alcance, profundidade acadêmica e possibilidade objetiva de ser desenvolvida na prática da administração pública. Para dar continuidade à discussão, o próximo tópico será dedicado à complementaridade dos modelos e da proposta. 


\subsection{A Complementaridade entre a Proposta e os Modelos de Administração Pública}

Ao longo deste artigo, foram apresentadas as bases epistemológicas para a reconceituação da administração pública. Os modelos e a proposta de administração pública também foram discutidos a partir dessas bases extraídas da teoria da delimitação dos sistemas sociais. Essa teoria concebe a sociedade sob a forma multicêntrica, ou seja, de múltiplos enclaves, entre os quais está o mercado. Nessa perspectiva, a sociedade politicamente articulada tem como referência a multidimensionalidade humana. Por isso mesmo, ela requer espaços múltiplos em que o ser humano possa realizar o exercício da política, da convivialidade e da economia oudo mercado.

Muito embora seja uma concepção heurística de sociedade, ela tem a possibilidade objetiva de se concretizar, uma vez que a realidade social se constitui, sempre, de sistemas mistos. Mesmo nas modernas sociedades de mercado, nas quais predomina o espaço da economia, existem espaços ou enclaves delimitados em que há a possibilidade objetiva do exercício da multidimensionalidade humana. Negar essa possibilidade seria admitir a existência de um sistema social puro, o que, do ponto da vista da ciência e da realidade social, é inconcebível (RAMOS, 1981).

O conceito de administração pública desenvolvido neste artigo também se estrutura sob a premissa de uma sociedade multicêntrica, articulada a partir da multidimensionalidade humana. De acordo com esse conceito, os conhecimentos sobre a multidimensionalidade do ser humano, a constituição multicêntrica da sociedade e as condições objetivas de cada sociedade, no seu conjunto, são essenciais para a prática da administração pública e consequente provisão dos serviços públicos.

Assim como o ser humano e a sociedade não podem ser entendidos de maneira fragmentada ou linear, também a prática da administração pública não pode ocorrer a partir de um modelo que privilegie apenas a burocracia pública ou o mercado como provedores e alocadores dos serviços públicos. Também não pode privilegiar, de forma isolada, uma proposta de administração pública cujo foco seja a democracia, sem estratégia objetiva para produzir os demais bens e serviços públicos. A prática da administração pública em uma sociedade multicêntrica requer, portanto, múltiplas práticas e modelos, cada qual apropriado ao seu espaço na sociedade. Em outros termos, os modelos e propostas emergentes da administração pública, quando analisa- 
dos isoladamente, apresentam sérias restrições, pois partem do pressuposto de que o ser humano e a sociedade são unidimensionais. Tais modelos $e$ propostas, contudo, quando utilizados nos espaços que lhes são próprios, em uma sociedade multicêntrica, politicamente articulada, podem ser de valia para a administração pública. Logo, em termos de possibilidade objetiva, os atuais modelos e propostas de administração pública podem vir a ser mais eficientes e eficazes, quando vistos de forma complementar, a partir de uma mesma base epistemológica que concebe a sociedade sob a perspectiva multicêntrica e politicamente articulada.

A administração pública convencional utiliza a burocracia pública para a produção dos serviços públicos. Essa estratégia de produção pertence ao espaço da economia ou do mercado, uma vez que, no seu âmbito, a dominação é legítima. O modelo é necessário para a produção de serviços públicos em larga escala e em tarefas de rotina elevada; é necessário, por exemplo, para a realização das atividades em campanhas de vacinação, na área de saúde pública; em atividades de controle e contabilidade, na área de arrecadação de impostos; e em policiamento ostensivo, na área de segurança pública. Sua eficiência requer um modo de gestão que permita o uso de estruturas de consentimento, já descritas em outro tópico deste artigo. Quando utilizado em uma sociedade politicamente articulada, requer formas de controle social e de accountability que o tornem responsivo à sociedade (VIGODA, 2002). Dessa maneira, o modelo se conforma ao espaço que lhe é pertinente, delimitado pelo controle que lhe impõe a sociedade.

A nova gestão pública utiliza a burocracia pública e privada para a produção dos serviços públicos. Esse modelo pertence ao espaço da economia ou do mercado, nele se utilizam estratégias e tecnologias que são próprias do mercado. Ele é necessário para a produção em larga escala e para a execução de atividades em que o mercado é eficiente alocador de bens e serviços, por exemplo: para a produção de vestimentas especiais para hospitais e postos de saúde pública, na área da saúde pública; na construção de escolas, na área de educação; e na construção de estradas e usinas para a geração de energia, na área de logística, transportes e energia. Também esse modelo requer controle social e accountability, de maneira a tornar as suas atividades transparentes para a sociedade (KLINGNER, NALBANDIAN, ROMZEK, 2002). É necessário lembrar que seu espaço é restrito ao mercado, portanto à esfera privada. Cabe à sociedade politicamente articulada, nas circunstâncias que lhe são próprias, definir os meios para delimitá-lo dentro desse espaço. 
O novo serviço público é uma proposta de administração pública emergente que tem seu foco principal voltado para o espaço democrático da sociedade. A base epistemológica da proposta se coaduna com o conceito de administração pública desenvolvido neste artigo. É oportuno lembrar, no entanto, que essa proposta é limitada quando os demais modelos são aplicados a partir de outra base epistemológica. Faltam-os mecanismos de eficiência dos demais modelos para torná-la eficaz, para permitir que as suas propostas sejam exequíveis. Portanto, para viabilizar a proposta do novo serviço público, é necessário que a sociedade seja politicamente articulada, nos moldes de uma sociedade multicêntrica, e que ela espelhe a multidimensionalidade humana. A proposta do novo serviço público abrange os demais modelos e seus exemplos. São peculiares a ela, no entanto, os exemplos de articulação política e de liderança para envolvimento das forças do tecido social na produção dos serviços públicos que requerem a participação de múltiplas instâncias sociais. O controle social e a accountability lhe são inerentes (DENHARDT, DENHARDT, 2003). O foco da proposta está delimitado ao espaço político, em que pesem as suas estratégias de articulação e liderança para o envolvimento de outras instâncias sociais.

Os modelos e a proposta de administração pública, como foi discutido até aqui, são necessários para a produção dos serviços públicos. Eles se complementam como estratégias para a produção do bem público em uma sociedade politicamente articulada. Há, no entanto, espaços na esfera pública que não são contemplados por esses modelos e proposta. As comunidades, as organizações sociais de toda sorte e o cidadão - partícipes na produção dos serviços públicos -, também fazem parte da sociedade politicamente articulada. Há necessidade de formular novos modelos de administração pública que abranjam as instâncias sociais como coprodutoras dos serviços públicos. Essa é uma lacuna que precisa ser preenchida na administração pública. Da mesma forma, as atividades de responsabilidade social das empresas que produzem o bem público necessitam de uma proposta que as incorpore à administração pública. $\mathrm{O}$ conjunto composto pelos modelos $e$ pela proposta de administração pública, pela área de responsabilidade social das empresas e pelas diversas instâncias sociais, quando agindo de forma complementar, pode coproduzir o bem público com a eficiência, a eficácia e a efetividade demandadas pela sociedade. Sob a perspectiva da administração pública, a questão estratégica mais importante é definir a articulação e o modelo ou os modelos necessários a cada espaço da sociedade politicamente articulada. 
A complementaridade dos modelos e da proposta de administração pública, discutida neste artigo, requer uma estratégia de implementação em que os serviços públicos sejam coproduzidos pelas diversas instâncias e organizações da sociedade politicamente articulada. A coprodução em rede do bem público é uma estratégia, por excelência, para que os serviços públicos sejam produzidos de maneira eficaz. Muito se tem escrito sobre esse assunto, porém pouco do ponto de vista da complementaridade dos modelos e da proposta de administração pública. Entre os autores que discutiram a coprodução dos serviços públicos se destacam Cooper e Kathi (2005), Marschall (2004), Sundeen (1985), Levine (1984), Brudney e England (1983), Rosentraub e Sharp (1981), Kiser e Percy (1980), e Vhitaker (1980). Nesse ponto é importante esclarecer que a implantação da coprodução dos serviços públicos, quando vista sob a perspectiva da complementaridade dos modelos e da proposta de administração pública, supera as dificuldades impostas pelo fenômeno do hollow state (MILWARD, 1996; MILWARD e PROVAN, 2000) e do thinning of institutions (TERRY, 2005).

Em suma, a coprodução dos serviços públicos a partir da complementaridade dos modelos e da proposta de administração pública pode ocorrer (1) por meio da organização burocrática em que haja a gestão participativa obtida por meio de estruturas de consentimento; (2) por meio das organizações sociais com características isonômicas; (3) por meio de comunidades engajadas com a produção do bem público; (4) por meio da responsabilidade social das empresas, quando elas produzem um bem público, fato amplamente ignorado pelos estudiosos da administração pública; e (5) por meio do cidadão, em seu papel de ser político, produzindo o bem público. Esse conjunto pode constituir-se em rede, tornando possível a complementaridade de modelos e da proposta discutida ao longo deste artigo.

A estratégia de coprodução do bem público, a partir da complementaridade dos modelos e da proposta, requer atividades de coordenação política além da atividade usual de coordenação na organização burocrática pública. Também a liderança da rede que coproduz o bem público, interagindo em todos os espaços da sociedade politicamente articulada, tem atribuições mais complexas do que aquelas exercidas no âmbito da burocracia. Faz-se, portanto, imperativo o preparo de coordenadores e líderes para agir em sistemas de coprodução dos serviços públicos que adotem a complementaridade dos modelos e da proposta de administração pública discutidos neste artigo. Esse é, provavelmente, o mais importante desafio das 
escolas que formam administradores públicos, seja em nível de graduação ou pós-graduação (NALBANDIAN, 1999). O próximo tópico contém algumas considerações a esse respeito.

\section{Considerações Finais}

Ao longo deste artigo elaborou-se a reconceituação da administração pública baseada em categorias da teoria da delimitação dos sistemas sociais. Também foram descritos e discutidos os modelos de administração pública, a complementaridade entre os modelos e a proposta de administração pública, além das diversas instâncias que podem produzir e coproduzir o bem público. Ainda foram levantadas algumas considerações sobre a necessidade de prepararem lideranças para a coprodução do bem público, quando os modelos e a proposta de administração pública são utilizados de forma complementar. As considerações finais deste artigo, portanto se voltam para esse assunto.

É importante ressaltar que, para a implementação da complementaridade dos modelos e da proposta discutida ao longo deste artigo, impõe-se a estratégia da coprodução do bem público. Da mesma forma, o processo de articulação política, essencial para a implantação da complementaridade, exige líderes de redes de coprodução capazes de servir ao cidadão e à comunidade nos moldes propostos por Denhardt e Denhardt (2006), Nair (1994), Wheatley (1994) e Block (1993).

Essas lideranças podem ser preparadas pela reflexão-na-ação e pelos meios de educação utilizados em escolas que preparam lideranças para a administração pública. A reflexão-na-ação ocorre pela aprendizagem individual experienciada (SCHÖN, 2000). Existem outros meios para estimular a reflexão-na-ação, como, por exemplo, a pesquisa-ação e a pesquisa participante. A reflexão-na-ação ocorre quando se estabelece um diálogo daquele que pratica ou praticou a ação consigo mesmo (CUNLIFFE; JUN, 2005). Essa aprendizagem requer a ausência de qualquer constrangimento externo e o exercício da liberdade da mente humana. Ela se insere na discussão feita por Guimarães (2003) sobre a organização de aprendizagem no setor público.

Cursos que pretendem preparar administradores públicos para atuar em sistemas de coprodução do bem público, em que os modelos e a proposta de administração pública são utilizados de forma complementar, precisam oferecer uma base sólida de conhecimentos das humanidades. Compreen- 
der a questão da participação do cidadão na comunidade e os meios de facilitar esse processo é de capital importância para o preparo das lideranças desses sistemas. Também a experimentação deve ser privilegiada, pois os estudantes precisam agir na vida e praticar a reflexão-na-ação para alicerçar o saber. Tal intento cobra desenvolver a pesquisa no meio em que se insere a ação, para criar o saber sobre a comunidade em que se pretende agir.

A participação do cidadão em sua comunidade agrega uma variável importante para a formação do administrador público, uma vez que a responsabilidade pela produção do bem público passa a ser, também, das pessoas da comunidade. Nesse caso, é insuficiente a formação do administrador como um generalista. Essa nova realidade requer conhecimentos sobre ciência política, sociologia, antropologia, filosofia e sobre liderança de redes para a coprodução do bem público. Esses conhecimentos não descaracterizam a formação do administrador, muito pelo contrário, a sua abrangência multidisciplinar permite que ele compreenda melhor a sociedade ou a comunidade e suas complexas dimensões.

A pesquisa nas escolas de administração pública também pode contribuir para a implantação da proposta de coprodução do bem público nos moldes em que ela foi desenvolvida neste artigo. Por exemplo, observar como ocorre a articulação política para a formação de redes de organizações sociais ou como se realiza a liderança e a coordenação da coprodução do bem público, entendida a liderança como um ato de servir ao cidadão e à comunidade. As questões relacionadas com o trabalho e a ocupação, as relações simbólicas na comunidade e a ação administrativa nos espaços das organizações sociais impõem ser mais bem pesquisadas e estudadas.

Vale relembrar, finalmente, que o conceito de administração pública desenvolvido neste artigo tem como centro o ser humano, único e multidimensional, partícipe da sociedade multicêntrica articulada politicamente. Mediante esse conceito, foi possível demonstrar a complementaridade dos modelos de administração pública. Estudar e pesquisar a administração pública, sob esse prisma, é o desafio que se coloca a todos aqueles que buscam desenvolver e implantar um novo serviço público para servir ao interesse público. 


\title{
Models of Public Administration as Complementary Strategies for Co-production of Public Good
}

\begin{abstract}
Public administration is re-conceptualized based on the Social Systems Delimitation Theory, which focuses the society politically articulated considering the concept of the human being, as the main actor in the construction of society. Models of public administration are discussed herein, considering this re-conceptualization aiming at showing it as complementary to one another and to the co-production network of public goods from which they are a part of. Human existence fulfills itself in multiple spaces, each of which has its own needs and exigencies. These models of public administration apply to this social reality. When analyzed under this perspective, such models are complementary to one another, each one with its own space of applicability in a politically articulated society; consequently, public good is co-produced in network, and these models are a part of this network, as well as of the other community stances, of which society consists of. In sum, some considerations on research and study on administration are made based on these models of public administration as complementary strategies for co-production of public good.
\end{abstract}

Key-words: Public administration. Models. Co-production. Complementary Strategy. Multidimensionality.

\section{Referências}

ARENDT, $\mathrm{H}$. The human condition. Chicago: The University of Chicago Press, 1958.

BARZELAY, M. The new public management. Berkeley: University of California Press, 2001.

BATTISTELLI, F; RICOTA, G. The rhetoric of management control in Italian cities: constructing new meanings of public action. Administration \&

Society, v. 36, n. 6, p. 661-687, 2005.

BELLONE, C. J. Organization Theory and the New Public

Administration. Toronto: Allyn and Bacon, Inc., 1980. 
José Francisco Salm • Maria Ester Menegasso

BLOCK, P. Stewardship: choosing service over self interest. San Francisco, CA: Berrett-Koeler Publishers, Inc. 1993.

BOX, R. C.; MARSHALL, G. S.; REED, B. J.; REED, C. M. New public management and substantive democracy. Public Administration Review. v. 61, n. 5, p. 608-619, 2001.

BRUDNEY, J. L.; ENGLAND, R. E. Toward a definition of the coproduction concept. Public Administration Review. v. 43, n. 1, p. 59-65, 1983.

CAMPBELL, K. B. Theorizing the authentic: identity, engagement, and public space. Administration \& Society. v. 36, n. 6, p. 688-705, 2005.

COOPER, T. L.; KATHI, P. C. Neighborhood councils and city agencies: a model of collaborative coproduction. National Civic Review. p. 43-53, Spring, 2005.

CONFORD, F. M. The republic of Plato. New York: Oxford University Press, 1976.

COSTA, F. L. Programa de Estudos e Pesquisas em reforma do Estado e Governança. Revista de Administração Pública, Rio de Janeiro, v. 34, n. 1, p. 267-70, 2000.

CUNLIFFE, L.; JUN, J. S. The need for reflexivity in public administration. Administrtion \& Society. v. 37, n. 2, p. 225-242, 2005.

DELEON, L.; DENHARDT, R. B. The political theory of reinvention. Public Administration Review, v. 60, n. 2, p. 89-97, 2000.

DENHARDT, J. V.; DENHARDT, R. B. The new public service: serving rather than steering. New York: M. E. Sharpe, 2003.

DENHARDT, R. B.; DENHARDT, J. V. The dance of leadership. New York: M. E. Sharpe, 2006.

FRANKL, E. V. Em busca de sentido. Petrópolis: Editora Vozes, 1991.

GAETANI, F. O recorrente apelo das reformas gerenciais: uma breve comparação. Revista do Serviço Público, Brasília, v. 54, n. 4, p. 21- 41, 2003.

GERMINO, D. Political philosophy and the open society. Baton Rouge: Louisiana State University Press, 1982. 
GOODSELL, C. T. The concept of public space and its democratic manifestations. American Review of Public Administration. v. 33, n. 4, p. 361-383, 2003.

GUIMARÃES, T. A. Explorando o construto organização de aprendizagem no setor público: uma análise em órgão do poder executivo federal brasileiro. Organização \& Sociedade, Salvador, v. 10, n. 27, p. 111-125, 2003.

HIRSCHMAN, A. The Passions and the interests: political arguments for capitalism before Its triumph. Princeton: Princeton University Press, 1978.

JAGUARIBE, H. J. A democracia grega. Brasília: Editora Universidade de Brasília, 1982.

KETLL, D. F. The global public management revolution. Washington: Brookings Institutions Press, 2000.

KISER, L. L.; PERCY, S. L. The concept of coproduction and its implications for public service delivery. Workshop in Political Theory and Policy Analysis. San Francisco, p. 13-16, April, 1980.

KLINGNER, D. E.; NALBANDIAN, J.; ROMZEK, B. S. Politics, administration, and markets: conflicting expectations and accountability. American Review of Public Administration, v. 32, n. 2, p.117-144, 2002.

LEVINE, C. H. Citizenship and service delivery: the promise of coprodution. Public Administrtion Review, v. 44, p. 178-84, 1984.

MARINI, C. Aspectos contemporâneos do debate sobre reforma da administração pública no Brasil: a agenda herdada e as novas perspectivas. VIII Congresso Internacional Del Clad sobre la Reforma Del Estado y de la Administración Pública, Panamá: p. 28-31, 2003.

MARSCHALL, M. Citizen participation and the neighborhood context: A new look at the coproduction of local public goods. Political Research Quarterly. v. 57 , n. 2, p. 231-244, 2004.

MASLOW, A. H. A theory of human motivation. Psychological Review, v. 50, p. 370-396, 1943.

MILWARD, H. B. Symposium on the hollowstate capacity. Control, and performance in organizational settings. Journal of Public Administration Research \& Theory, v. 6, p. 193- 195, 1996. 
José Francisco Salm • Maria Ester Menegasso

MILWARD, H. B.; PROVAN, K. G. Governing the hollow state. Journal of Public Administration Research \& Theory, v. 10, p. 359-377, 2000.

NAIR, K. A higher standard of leadership: lessons of the life of Gandhi. San Francisco, Ca: Berrett-Koeler Publishers, Inc., 1994.

NALBANDIAN, J. Facilitating community, enabling democracy: new roles of local gvernment managers. Public Administration Review, v. 59, p. 187198, 1999.

NOGUEIRA, M. A. Sociedade civil, entre o político-estatal e o universo gerencial. Revista Brasileira Ciências Sociais, v. 18, n. 52, 2003.

PACHECO, R. S. Administração pública nas revistas especializadas - Brasil, 1995-2002. Revista de Administração de Empresas, São Paulo, p. 63-71, 2003

PATTAKOS, A. N. The search for meaning in government service. Public Administration Review, v. 64, n. 1, p. 106-112, 2004.

POTOSKI, M.; PRAKASH, A. The regulation dilema: cooperation and conflict in envirnmental gevernance. Public Administration Review, v. 64, n. 2, p. 152163, 2004.

PUTNAM, R. Bowling alone. New York: Simon \& Schuster, 2000.

RAMOS, A. G. A nova ciência das organizações. Rio de Janeiro: Editora Fundação Getúlio Vargas, 1981.

RAMOS, A. G. Administração e Contexto Brasileiro. Rio de Janeiro: Editora Fundação Getúlio Vargas, 1983.

ROBERTS, N. Public deliberation in age of direct citizen participation.

American Review of Public Administration, v. 34, n. 4, p. 315-353, 2004.

ROSENTRAUB, M. S.; SHARP, E. B. Consumers as producers of social service: coproduction and the level of social services. Southern Review of Public Administration, v. 4, n. 4, p. 502-539, 1981.

SANTOS, M. O espaço em questão. São Paulo: Editora Marco Zero Ltda., 1988 . 
SHAFRITZ, J. M.; HYDE, A. C. Classics of public administration. Oak Park: Moore Publishing Company, INC., 1978.

SCHÖN, D. A. Educando o profissional reflexivo. Porto Alegre: Artmed Editora, 2000.

SPICER, M. Public administration, the history of ideas, and the reinventing government movement. Public Administration Review, v. 64, n. 3, p. 353362, 2004.

SPICER, M. W. Determinism, social science, and public administration: lessons from Isaiah Berlin. American Review of Public Administration, v. 35, n. 3, p. 256-269, 2005.

SUNDEEN, R. A. Coproduction and communities: implications for local administrtors. Administration \& Society, v. 16, p. 387-402, 1985.

TERRY, L. The thinning of administrative institutions in the hollw state. Administration \& Society, v. 37, n. 4, p. 426-444, 2005.

VENTRISS, C. The rise of entrepreneurial state governments in the United States: the dilemma of public governance in an era of globalization.

Administrative Theory \& Praxis, v. 24, n. 1, p. 81-102, 2002.

WHEATLEY, M. J. Leadership and the new science: learning about organization from an orderly universe. San Francisco, CA: Berrett-Koeler Publishers, Inc., 1994.

VIGODA, E. From responsiveness to collaboration: governance, citizens, and the next generation of public administration. Public Administration Review, v. 62 , n. 5 , p. 527- 540, 2002.

VÖEGELIN, E. A nova ciência política. Brasília: Editora Universidade de Brasília, 1952

Order and history: Plato and Aristotle. Baton Rouge: Louisiana State University Press, 1977.

Anamnesis. Notre Dame: University of Notre Dame, 1978.

WALDO, D. The enterprise of public administration. Novato, Ca.: Chandler \& Sharp Publications Inc., 1980. 
José Francisco Salm • Maria Ester Menegasso

WEBER, M. Economy and society. Berkeley: University of California Press, 1978.

WHITAKER, G. P. Coproduction: citizen participation in service delivery.

Public Administration Review, v. 40, p. 240-246, 1980.

WILCKEN, P. Império à deriva: a corte portuguesa no Rio de Janeiro, 18081821. Rio de Janeiro: Editora objetiva Ltda., 2004.

WILSON, W. The study of administrtion. Political Science Quarterly, v. 2, n. 2, p. 197-222, 1887. 